\title{
Mulheres nos Slam's: de musas a poetas
}

\author{
Ana Claudia Antunes Brizola ${ }^{1}$ \\ Bruna Lourenso $^{2}$ \\ Recebido em maio de 2019 \\ Aceito em outubro de 2019
}

\section{RESUMO}

O artigo ${ }^{3}$ aborda a inserção das mulheres na cultura a partir de sua participação no Movimento Slam, em contraposição às opressões de gênero, raça, classe, sexualidade e acessibilidade. Entendemos que a cultura deve ser democrática e acessível e esse movimento caminha nesse sentido, por serem batalhas de poesias marginais, nas quais são abordadas em sua maioria questões sociais, que muitas vezes trazem tanto visões gerais, quanto particulares como experiências de vida. É a partir da perspectiva das slammers que analisamos essa participação, buscando compreender as vivências e a construção de significados de cada poeta; seja por raça, identidade de gênero, sexualidade, geração, classe social, escolaridade ou a partir das subjetividades expressas por meio da poesia. Para realização da pesquisa entrevistamos doze poetas de diferentes regiões, sexualidades, religiões, profissões, raças e classes, via whatsapp e também pessoalmente em uma edição do "Slam das Gurias" localizado no centro de Curitiba. Movimentamos trechos de suas poesias e bibliografias referentes aos movimentos Feminista e Mulherismo. Concluímos que o Slam representa um movimento empoderador no qual as mulheres plurais ocupam espaços físicos e simbólicos, visibilizando suas vivências e pautas através da poesia.

Palavras-chave: Mulheres; Cultura; Slam; Poesia; Subjetividade.

\section{RESUMEN}

El artículo aborda la inserción de las mujeres en la cultura a través de su participación en el Movimiento Slam, en oposición a la opresión de género, raza, clase, sexualidad y accesibilidad. Entendemos que la cultura debe ser democrática y accesible y este movimiento va en esta dirección, ya que son batallas de poesía marginal, en que la mayoría abordan los problemas sociales, que a menudo aportan puntos de vista tanto generales como privados, como experiencias de la vida. Es por la perspectiva de las slammers que analizamos esta participación, buscando comprender las experiencias y la construcción de significados de cada poeta; sea por raza, identidad de género, sexualidad, generación, clase social, educación o desde las subjetividades expresadas a través de la poesía. Para llevar a cabo la investigación, entrevistamos a doce poetas de diferentes regiones, sexualidades, religiones, profesiones, razas y clases, por WhatsApp y también personalmente en una edición de "Slam das Gurias", ubicado en el centro de

${ }^{1}$ Universidade Federal do Paraná, graduação em Bacharelado em Sociologia. Pertencente ao grupo de pesquisa Planejamento e Desenvolvimento Urbano e Regional, recebimento de bolsa de extensão no período de maio/2019 a dezembro/2019. Participante voluntária do projeto de extensão "Arte e Direito à Cidade".

${ }^{2}$ Universidade Federal do Paraná, graduação em Bacharelado em Sociologia. Pertencente ao grupo de pesquisa Planejamento e Desenvolvimento Urbano e Regional, recebimento de bolsa de extensão no período de maio/2019 a dezembro/2019. Idealizadora e participante voluntária do projeto de extensão "Arte e Direito à Cidade”.

3 Agradecemos as contribuições dos pareceristas, que foram levadas em consideração para o aprimoramento do presente artigo e também suscitaram diversas reflexões até mesmo para trabalhos posteriores. 
Curitiba. Usamos extractos de su poesía y bibliografías referentes a Movimientos feministas y mujerlismo. Concluimos que Slam es un movimiento de empoderamiento en que las mujeres plurales ocupan espacios físicos y simbólicos, haciendo visibles sus experiencias y reclamar a través de la poesía.

Palabra clave: Mujeres; Cultura; Slam; Poesía; Subjetividad.

Os movimentos culturais são fundamentais para conquistas de liberdades, expressão das subjetividades, reflexões e reivindicações. Entendemos que a cultura deve ser democrática e acessível, os Slam's caminham nesse sentido, por serem batalhas de poesias marginais, nas quais a maioria das poesias abordam questões sociais, que muitas vezes tratam tanto de visões gerais, quanto particulares como experiências de vida. É a partir da perspectiva das slammers que o proposto trabalho analisa essa participação, buscando compreender não apenas as particularidades de "ser mulher", mas as vivências de cada uma incluindo amplas categorias que perpassam diferentes trajetórias e a construção de significados; seja por raça, identidade de gênero, sexualidade, geração, classe social, escolaridade ou a partir da subjetividade que cada poeta expressa.

As batalhas de poesias ocorrem em espaços abertos, onde qualquer pessoa pode participar sem necessitar formação técnica. Ocorre de forma gratuita (tanto para quem recita poesia, quanto para quem assiste) em sua maioria em locais públicos, como em ruas e praças. As mulheres vêm conquistando cada vez mais visibilidade e igualdade dentro desse movimento cultural.

Ao longo da história as mulheres foram estigmatizadas ${ }^{4}$, discriminadas e colocadas à margem de um reconhecimento cultural, artístico e científico. Sendo descritas por homens, que lhes impunham uma dominação patriarcal, na qual as mulheres tinham papéis sexuais bem demarcados, além de serem associadas aos instintos maternos e dóceis "naturais" da feminilidade. Essa ordem social era em parte real, em parte idealizada, tendo em vista, que não se aplicava a todas as mulheres, e sim, em sua maioria à classe burguesa; as mulheres pobres, negras e mães que criavam

\footnotetext{
${ }^{4}$ Compreendemos o conceito de estigma a partir da discussão feita por Parker e Aggleton (2001, p. 10-11) do conceito de Erving Goffman, segunda a qual é uma forma da sociedade desvalorizar certos indivíduos devido às suas diferenças, tendo uma centralidade na produção e reprodução das relações de poder.
} 
os filhos sozinhas transitavam sobre essas barreiras patriarcais, primeiro porque tinham que trabalhar para sobreviver, andar pelas ruas à noite ao voltar do trabalho, e muitas tinham de ser a expressão máxima de força dentro de casa. Contudo, as mulheres estavam escrevendo, pensando, fazendo ciência desde muito antes do reconhecimento, porém a estrutura machista e patriarcal abafava o protagonismo e autonomia dessas mulheres.

Com a ascensão do modernismo no século XX, se destacam grandes escritoras, cientistas, artistas, como Virginia Woolf, Simone de Beauvouir, Rita Felski, entre outras que marcaram esse momento de reconhecimento da produção feminina. Mulheres entram "com o pé na porta" como diria Woolf, na disputa pelas narrativas, para que elas tenham espaços públicos e direitos sobre si mesmas. Nesse sentido, buscamos discutir a importância das mulheres nos slam's analisando como elas se colocam nos espaços, quais suas pautas, suas reivindicações e seu entendimento sobre esse movimento cultural em suas particularidades, buscando o reconhecimento das diferenças entre gêneros e intragêneros acerca dos movimentos de mulheres, mais especificamente, das mulheres negras.

\section{Metodologia}

Para a realização desta pesquisa foram aplicadas entrevistas semiestruturadas por meio de Whatsapp e pessoalmente em uma edição do "Slam das Gurias”, buscou-se permitir que as poetas se expressassem de forma mais livre, as perguntas em geral foram feitas no sentido de buscar significações tanto dos espaços, quanto das relações sociais e das poesias. Percebemos que as respostas virtuais estavam mais desenvolvidas devido ao tempo que tiveram para responder. Algumas informações coletadas nos questionários não estão no presente artigo por não considerarmos relevantes para os objetivos propostos nessa pesquisa. Foram entrevistadas doze mulheres slammers de diferentes raças, religiões, sexualidades, classes, linguagens, escolaridades, profissões, idades, identidades e regiões, buscando que cada uma pudesse expressar suas subjetividades a partir das próprias vivências e significações, afinal, as poesias e 
respostas versam sobre suas próprias experiências, reflexões, trajetórias, e demandas a partir de cada olhar. Também foram utilizados trechos de suas poesias a fim de observar como as vivências apontadas nos questionários se traduzem nas performances poéticas.

Devido ao conteúdo do presente trabalho e das colocações das próprias slammers, optamos por utilizar sempre o termo poeta ao invés de poetisa, pois se compreende que não é um termo especificamente masculino, e que sempre se criam novas palavras para definir mulheres. No entanto, mesmo quando ainda não eram reconhecidas mulheres, já faziam poesia e literatura. Optamos também por substituir os nomes das entrevistadas por nomes de flores para preservar sua privacidade, entretanto os trechos das poesias citados seguem com os nomes das autoras, pois é possível encontra-las publicadas nas redes sociais dos Slam's.

Movimentamos bibliografias que abordam perspectivas históricas sobre a representação das mulheres na sociedade, como por exemplo, Simone de Beauvoir que desnaturaliza o que significa ser mulher, que está além do aspecto biológico, adentrando questões culturais, assim como faz Judith Butler ao questionar não apenas a concepção de "sexo", como também problematiza o "gênero", e a conceituação de "Mulherismo" encontrada também em textos de Carneiro. Utilizamos a discussão de Fleury sobre a conceituação de cultura, de como o autor aponta que não há uma cultura legitima ou não, e sim que todas suas expressões são válidas independente da institucionalização, já que o slam se encontra nesse paradoxo: um movimento legítimo e ao mesmo tempo "marginal” com relação à institucionalização. Outra discussão utilizada é a definição de estigma feita por Goffman. Por fazermos parte do Movimento Slam, assim como da militância pelos direitos das mulheres, nos interessamos pela presente pesquisa. A escolha do tema se deu pela importância do reconhecimento da literatura produzida por mulheres, buscando compreender as pluralidades femininas e destacar a importância de estudos das perspectivas sociológicas sobre os Slam's e a participação das mulheres nesse movimento.

\section{Slam e poesia marginal:}


Tirar a arte de um pedestal elitista, tanto monetário, como geográfico.

(Amarílis, 2019).

Os Slam's são batalhas de poesias, que foram idealizadas nos Estados Unidos, na cidade de Chicago por Marc Kelly Smith na década de 1980, e que tomaram proporção mundial. No Brasil, o movimento foi inserido apenas em 2008, pela poeta Roberta Estrela D’Alva que trouxe em sua bagagem a experiência que viveu em sua viagem no exterior. Atualmente os Slam's têm se difundido no Brasil inteiro, sendo somente no estado do Paraná, seis Slam's permanentes ativos que ocorrem uma vez ao mês: Slam das Gurias (Centro, Curitiba), no qual homens podem participar como plateia, mas apenas as mulheres podem recitar e julgar; Slam Alferes Poeta (Parolin, Curitiba), primeiro e, atualmente, único Slam que ocorre em uma periferia no Paraná, neste todas e todos podem assistir e recitar; Slam Contrataque (Centro, Curitiba), é atualmente o Slam ativo mais antigo do estado, todas e todos podem participar; Slam da Resistência Surda (Centro, Curitiba), é um evento bilíngue Português/Língua Brasileira de Sinais (LIBRAS), mas o foco é promover visibilidade para a comunidade surda, este ocorre pontualmente devido às dificuldades de organização com intérpretes; Slam Pé Vermelho (Maringá) se trata do único Slam realizado no interior do Paraná, no qual todas e todos podem participar; Slam de La Frontera (Foz do Iguaçu) é o mais recente. O primeiro do estado foi o Slam do Verbo Divino que realizou três edições no município de São José dos Pinhais, mas atualmente tornou-se um Sarau que ocorre pontualmente, tendo perdido o caráter de competição. Cada um desses Slam's realizam edições finais anuais com objetivo de enviar três finalistas para o Slam Regional que ocorre em nível estadual, esse por sua vez, envia uma ou um representante para o Slam Brasil, do qual a vencedora ou vencedor representa o país no campeonato internacional. Cada Slam possui regras específicas de funcionamento, mas no geral o júri não precisa ter formação técnica se voluntariando no momento de cada evento; não é permitida utilização de equipamentos audiovisuais, tão pouco instrumentos, pois, o foco são as poesias e apresentações. Mas para além da competição, são espaços de debates, união, fortalecimento, reflexividade, 
reconhecimento de identidades e diferenças, críticas sociais, ocupações de espaços físicos e simbólicos, sendo caracterizado pelo destaque da poesia marginal e por ocorrer no geral em espaços públicos e abertos.

O uso pela definição de "Poesia Marginal” por Slammers pressupõe a questão da exclusão social, política, econômica e cultural (no sentido institucionalizado), pois as narrativas de poetas participantes situam-se na perspectiva de que a arte (neste caso a poesia) é produzida à margem do reconhecimento institucional, que incorpora muitas vezes estigmas sobre as diversas vivências, instituindo o que é cultura legítima ou não. Por outro lado, nota-se a apropriação deste termo estigmatizado por parte das e dos poetas, como uma forma de ressignificação e reconhecimento da própria produção e acesso cultural, conforme discute o autor Laurent Fleury, ao analisar as disputas acerca do próprio conceito de "Cultura" apontando que este pode ser arbitrário como se seguisse leis como a natureza, quando na realidade a cultura é caracterizada pelas particularidades de suas instituições.

A noção de marginalidade nos remete ao conceito de estigma ${ }^{5}$ que tende a afastar determinadas categorias sociais, como minorias políticas de alguns espaços, posições e produções culturais, buscando a manutenção das classes dominantes como detentoras da "Cultura", como por exemplo, a valorização das obras de arte expostas em museus em contraste com as tentativas de criminalização da arte de rua que ocorreram recentemente nos dois últimos anos na cidade de Curitiba, como o Decreto

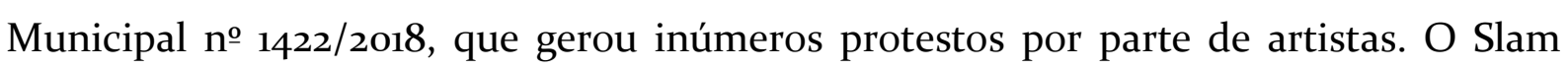
transita entre essas disputas pelo reconhecimento cultural, pelo fato de não ser um movimento institucionalizado, mas que ao mesmo tempo não é criminalizado e que, no entanto, carrega o estigma da marginalidade e o ressignifica a partir de poesias que versam sobre a subjetividade de cada poeta, em suas diferentes realidades econômicas, sociais, raciais, de gênero e sexualidade.

\section{Mulheres}

${ }^{5}$ Justificado na nota de rodapé ${ }^{1}$, (p. 2). 
Conjuntamente com a difusão do Movimento Slam, têm crescido a participação de mulheres diversas nesses espaços, tendo inclusive, vários Slam’s específicos pelo país. Além de ser um movimento de reconhecimento das diferenças, valoriza as vivências individuais e coletivas das poetas, as quais expõem diferentes opressões na forma de críticas sociais, demonstrando, através da arte, suas formas próprias de participação social, política e cultural. Assim, o Slam é também um movimento de reivindicação, significação e ocupação de espaços físicos e simbólicos, no sentido dos locais públicos como praças e ruas para construção de territórios representando "apropriação de uma parcela de espaço [...] por um determinado grupo de pessoas e período, legitimando-a como prática de uma atividade, reconhecido posteriormente pela comunidade e pela sociedade.” (RIBEIRO; MATOS, 1995 apud, HIRAMI, 2015 p. 18); e no sentido simbólico "espaço como forma de inscrição do tempo no mundo, no qual todo cidadão tem direito de usar e criar suas marcas dentro de um espaço social" (LÉFÈBVRE, 1991 apud, HIRAMI, 2015 p.8).

Conforme discute Mirian Adelman (2007, p. 23-46) ao citar Virginia Woolf, os olhares masculinistas sobre as mulheres as caracterizavam como "Anjos do Lar", naturalmente dóceis, passivas, feitas para a maternidade e o cuidado, seja para com o marido, com o lar ou com os filhos, ficando restritas às esferas privadas da sociedade, negando sua participação no mundo do trabalho, da política e até mesmo da circulação nas ruas ou em praças desacompanhadas ou em períodos noturnos. Esta ordem patriarcal mantinha o controle sobre os corpos femininos, estando à frente de decisões quanto à maternidade (discussões sobre o aborto, estão presentes no Brasil desde o século XIX), sobre sua sexualidade por inúmeras formas de repressão, e por suas análises de diferenciação sexual a partir do corpo masculino, pela perspectiva da "falta". A psicanalista e historiadora Elisabeth Roudinesco aprofundou-se nos estudos voltados principalmente para a questão da sexualidade a partir das teorias desenvolvidas por Sigmund Freud, como o "Complexo de Eléctra” pensado a partir do “Complexo de Édipo", que por sua vez, baseou-se no Mito de Édipo ${ }^{6}$ que caracteriza a mulher a partir da falta do falo, ou, na discussão biológica, pela falta do pênis. No

\footnotetext{
${ }^{6}$ Sobre o Mito de Édipo, ver Elisabeth Roudinesco, 2002.
} 
Complexo de Eléctra, tem-se a ideia de que a mulher sente inveja de possuir o pênis e por isso torna-se passiva na infância de apaixonar-se eroticamente pelo próprio pai, passando a enxergar a mãe como uma rival, e quando isso não ocorre essa mulher se distancia da heteronormatividade.

Essas teorias freudianas foram alvo de várias críticas feministas, como por exemplo, Simone de Beavouir, que primeiro desconstrói a concepção do "ser mulher" a partir do masculino, pois como a autora aponta, a mulher existe por si só e seus desejos sexuais, assim como seus prazeres são independentes do pênis, e também o fato de Freud ignorar as relações sociais e naturalizar as distinções sexuais entre homens e mulheres. Mas mesmo essas críticas apontadas por Simone de Beavouir não dão conta da questão da identidade de gênero de pessoas transexuais e mulheres travestis estudadas posteriormente pelas Teorias Queer na pós-modernidade, como fez Judith Butler ao desfazer tanto as noções de "sexo", quanto de "gênero" enquanto biologicamente determinantes, mas enquanto "performaticamente" construídas a partir de imposições sociais heteronormativas.

Segundo Louise Amaral e Daphne Fayad (2015), a partir dessas noções da falta nas teorias psicanalíticas criam-se duas figuras de mulher: "a mulher dita verdadeiramente feminina é marcada pelos signos da falta, como ilustram as pobres heroínas românticas, sempre sofredoras em nome do amor: dedicam-se, fazem sacrifícios, renunciam, compreendem, escutam, cuidam” e por outro lado as consideradas "transgressoras":

\footnotetext{
Uma figura de mulher, aparentemente em contraponto à primeira, se presentifica por um excesso que é a marca de seu fascínio: é a "poderosa", aquela que desconhece limites e que não se deixa intimidar pelos obstáculos, corajosa e decidida, sempre vai um pouco além, forçando os limites formais e informais postos pelas variadas formas de organização social. Sua coragem, sob esse ponto de vista, adviria do fato de que não tem mais nada a perder, pois já perdeu (AMARAL; FAYAD, 2015, p. 195).
}

Compreende-se assim que as visões masculinistas idealizavam a mulher feminina a partir da incompletude, estabelecendo papéis sexuais repressores, ao ponto que, aquelas e aqueles que ousavam "transgredir" a norma eram taxadas e taxados 
como "mulher-macho, sapatão, macho-fêmea, Maria-João, traveco, travestido, afeminado", entre outros estigmas e abjeções7. É perceptível o peso dos estigmas e outras violências vividas por mulheres travestis e transexuais no Brasil, o país foi responsável por $40 \%$ dos assassinatos de pessoas transgêneras no mundo inteiro nos últimos dez anos, segundo dados da Organização TransRespect. ${ }^{8}$ Como demonstra o relato da slammer Margarida, travesti, bissexual, preta que se declara transafrofeminista, moradora do interior de Minas Gerais: "Pelo fato de ser uma mulher preta e travesti, meu corpo não foi feito pra ocupar certos espaços e logo acabo sendo a única travesti preta do rolê e isso me incomoda bastante, lugares que tem muito homens e gente cisgênera me deixam meio travada" (2019).

Também foram relatadas situações de lesbofobia e assédio envolvendo homens slammers, o que demonstra como a sexualidade feminina ainda enfrenta dificuldades de ser respeitada. Girassol, lésbica, branca, poeta, slammer, moradora da Vila Autódromo no Bairro Cajuru em Curitiba, PR, Artista de Rua, artesã, em suas poesias sempre estão presentes denúncias das violências sofridas por razão de gênero e sexualidade: "Sejamos desacorrentadas do que o sistema produz, pois ser mulher nem de longe se reduz a amamentar, casar ou dar a luz". "Queremos as mulheres fora dos relacionamentos abusivos, as sapatões de mãos dadas e o fim do estupro corretivo" (Marihu, 2017).

Um homem que eu nem conhecia recitou uma poesia romântica olhando para
mim e para a minha amiga, depois insistiu em dizer coisas desrespeitando eu e
minha esposa. Já fui perseguida por um poeta, que mandou mensagens para
minhas amigas perguntando sobre mim mesmo tendo visto ele uma única vez.
Também já recebi várias "cantadas" de poetas por mensagens. Tenho a
impressão que muitos homens não me respeitam como mulher e lésbica
(Girassol, 2019).

7 Termos que remetem à LGBTIfobia, discriminações por razões de identidade de gênero e sexualidade, associadas à heteronormatividade, e termos naturalizadores das questões de gênero e reprodução, como "histéricas" para mulheres que não querem ser mães, ou "putas", "mulheres mundanas", "vadias", "mulheres da vida" para mulheres que exerciam liberdade sexual ou trabalhavam com atividades sexuais. Sobre abjeções ver: Mirian Adelman, 2007, p. 28.

${ }^{8}$ THOMAZ, 2018. 
Podemos analisar através dos estudos da sociolinguística como a língua também está dentro da binariedade dos sexos e do gênero confundido com o sexo biológico, assim, ao utilizarmos termos no masculino, como "homens" em referência aos seres humanos, ou "todos" em referência a uma totalidade de homens, mulheres e outros, acabamos criando generalizações e a prevalência do masculino ${ }^{9}$. Também no sentido da linguagem, notam-se as dificuldades de inclusão e acessibilidade de pessoas que não se comuniquem na Língua hegemônica de cada sociedade, como no caso do Brasil com relação à comunidade surda, marginalizando diversas pessoas através da imposição simbólica da oralidade e do português. Todas as entrevistadas consideram que por ocorrerem em espaços geralmente abertos, os slam's possibilitam acesso democrático, no entanto, os relatos da poeta Orquídea nos coloca o questionamento de que até que ponto esses e outros espaços são de fato inclusivos e democráticos. Sendo ela bissexual, negra, surda, atriz, feminista, ativista pelos direitos e visibilidade da comunidade surda e também organizadora do Slam da Resistência Surda em Curitiba, moradora do Bairro Capão da Imbuia em Curitiba; relata que uma pessoa surda possui dificuldades de interação em locais com a maioria de ouvintes devido a falta do auxílio de intérpretes, como também pela limitação do ensino da Língua Brasileira de Sinais pelo país. Recaindo em estigmas, como por exemplo, a ideia que pessoas surdas são mudas, quando na verdade elas falam:

E a feminista surda? Ela não consegue perceber, ela quer abrir uma porta pra poder se entender. Eu tô olhando. 'Olha a mudinha aqui'. Eu não sou mudinha, eu tô falando, eu sou surda. [...] Nós surdas somos violentadas, bloqueio de comunicação, não tem como falar com a polícia, eu sofro, sou desrespeitada. [...] O médico não sabe sinalizar, cadê o intérprete? (Negabi, 2017).

A divisão sexual do trabalho baseada na superioridade masculina que "aprisionava a mulher ao lar" também não compreendia a realidade de muitas mulheres, tais quais as mulheres negras que há muito tempo já trabalhavam inclusive em funções consideradas pesadas e masculinas, e sofreram inúmeras opressões resultantes do Regime Escravagista, que no Brasil permaneceu por três séculos, sendo

9 Ver: FREITAG; SEVERO, 2015. 
o país mais tardio em abolir a escravidão, e que no pós-abolição não forneceu nenhum tipo de amparo pra que as pessoas anteriormente escravizadas pudessem ter direitos básicos como moradia, emprego, educação e inserção na sociedade "livre", dessa forma restringindo suas possibilidades em amplos setores.

Durante o Modernismo, o movimento feminista protagonizou as mulheres brancas e burguesas com narrativas que buscavam romper com a sociedade vitoriana que tinha sua base na dominação patriarcal, mas universalizavam as mulheres a partir de perspectivas eurocêntricas (CARNEIRO, 2003, p. 117-132). No entanto, essa oposição não representava uma visibilidade acerca das questões raciais e culturais que caracterizavam principalmente o tipo de patriarcalismo dos países colonizados como o Brasil, que passaram por regimes escravocratas, porque por mais que se buscasse a liberdade dos corpos, dos desejos, da sexualidade e do pensamento, as dimensões de raça, etnicidade, cultura, homoafetividade feminina ainda permaneciam à margem, mesmo que algumas mulheres já estivessem debatendo essas questões, como esclarece Sojourner Truth, que relata nunca ter sido tratada com "cavalheirismo" ${ }^{10}$ por parte dos homens, como eram retratados nos romances os tratamentos dados às "damas sulistas”. Diante disso ela faz um questionamento:

\begin{abstract}
Trabalhei com o arado para plantar, levei os animais para as estribarias, e nenhum homem pôde mais do que eu. E não sou eu uma mulher? [...] Trabalhei e comi tanto quanto um homem o pode fazer - isto é, quando havia o que comer - e também aguentei o chicote tão bem quanto eles! [...] Tive treze filhos, e vi quase todos serem vendidos como escravos, e quando minha angústia de mãe me fez gritar apenas Jesus me ouviu, ninguém mais! E eu não sou eu mulher? (TRUTH, 1997 apud, ADELMAN, 2007, p. 29).
\end{abstract}

As mulheres negras encontraram-se diante de um paradoxo, uma vez que não se viam representadas pelo feminismo no Modernismo, devido ao não reconhecimento das opressões intragênero" ${ }^{11}$ e ao fato de que não se sentiam contempladas dentro do Movimento Negro que, por sua vez, não compreendia as opressões de gênero. Notamos

\footnotetext{
${ }^{10} \mathrm{O}$ termo está entre aspas por essa diferenciação marcante nas relações entre homens e mulheres tanto na literatura, quanto historicamente, que mostrava "mulheres boas" como sendo gentis e dóceis e "homens bons" como sendo cavalheiros, representando as diferentes significações atribuídas à "gentileza" entre homens e mulheres.

"Sobre opressões Intragênero, ver Sueli Carneiro, 2003.
} 
que as duas entrevistadas que não se declaram feministas são negras e moradoras de periferias, enquanto a poeta Margarida ressignifica o termo acrescentando suas demandas, se posicionando como transafrofeminista. Nove das entrevistadas se declaram feministas, sendo uma feminista interseccional. Observamos a partir das narrativas de algumas entrevistadas que embora o feminismo tenha se modificado e avançado em novas questões ao longo da história (desde o modernismo até os dias atuais), ainda segue com falhas de representatividade, assim algumas mulheres ativistas em várias lutas sociais não se identificam como pertencentes desse movimento, pois atualmente muitas correntes do feminismo ainda destacam pautas, vivências e padrões relacionados com a branquitude, às classes médias e à heteronormatividade.

Todas as entrevistadas concordam que as mulheres têm pautas diferentes entre si, e estão produzindo novas narrativas que se refletem em transformações concretas e subjetivas da realidade social e das relações sociais. Interseccionando questões de gênero e raça há teorias como o "Mulherismo", que segundo Alice Walker, estaria mais de acordo com as experiências de mulheres negras que lhes ocasionaria olhares "mulheristas", expondo desigualdades e opressões intragênero, como por exemplo, no regime da escravidão no qual mulheres brancas exerciam dominação sobre as mulheres negras, e como até hoje acontece, quando percebemos que a maioria das patroas são brancas, enquanto as empregadas domésticas são negras ${ }^{12}$.

No entanto, Patricia Hill Collins (2017), faz uma crítica ao Mulherismo, pois entende que faz prevalecer à questão de raça em detrimento da violência de gênero, pois segundo ela, algumas mulheres não reportavam casos de violência doméstica para proteger "seus irmãos de cor"; Angela Davis (2013) reconhece essas particularidades vividas pela população negra devido à escravidão, pois essa fez com que homens negros também fossem subordinados aos homens brancos, e como negras e negros eram vistas e vistos a partir da dimensão do trabalho pelos senhores, mulheres negras também eram "provedoras do lar", assim a condição das mulheres, segundo ela, era mais próxima de um matriarcado. No entanto, Angela Davis não se considera

${ }^{12}$ Sobre o assunto ver COLLINS, 2017. 
mulherista, mas feminista interseccional. Há também o Feminismo Negro, que surgiu na pós-modernidade buscando compreender as especificidades vividas por mulheres negras. Sueli Carneiro (2003, p. 118) descreve o Movimento como uma tentativa de “enegrecer o feminismo" intersecionando as pautas a partir do protagonismo de mulheres negras.

Conforme discutimos anteriormente, a própria ocupação dos espaços dos Slam's e o conceito de "Poesia Marginal" nos remetem à exclusão, principalmente quando os eventos ou as slammer's são de territórios estigmatizados, como o Complexo do Alemão no Rio de Janeiro retratado pelas grandes mídias como local de bandidagem, drogas e violência, fazendo com que moradoras e moradores sofram processos de criminalização, negligência e genocídio, que atingem principalmente a população negra. No caso de Curitiba, algumas regiões carregam "essas mesmas marcas", como por exemplo, a Vila Torres e o Bairro Parolin, que embora estejam localizados geograficamente próximos ao Centro da cidade, são compreendidas como periferias pois, como expõe Teixeira com base na discussão realizada por Lúcio Kowarick a partir do conceito de "cidade excludente" que considera "tomando exclusão não apenas no sentido econômico, mas também no tocante aos direitos básicos" (TEIXEIRA, 2019, p. 158-159).Três das entrevistadas moram nas regiões citadas acima, além de serem mulheres negras, são elas: Lírio , Tulipa e Lótus que também é lésbica.

Outra característica que essas slammers têm em comum é de chegarem "Com o pé na porta” como dizia Virginia Woolf, não só do patriarcado, mas também do racismo e outras desigualdades, lutando para transformar e denunciar as realidades sociais, políticas e culturais perversas, presentes na sociedade brasileira. As slammers também se apropriam e ressignificam os estigmas sofridos por elas conforme demonstra a poesia a seguir:

Mesmo em silêncio eu consigo ouvir os gritos de sofrimento, é tenso ver mais uma mãe enterrar seu filho.

Zona Norte ou Faixa de Gaza, não sei mais do que chamam, mas ainda é minha casa.

Bem aventurado o favelado que consegue sobreviver ao genocídio de 2018.

No mês da consciência negra onde a apropriação cultural reina, acabam de matar mais uma pérola preta (MC Martina, 2018). 
Lótus, realiza intervenções poéticas nos transportes e espaços públicos da cidade do Rio de Janeiro, compõe também um grupo que reúne jovens de várias favelas do Rio para debaterem novas políticas que substituam a chamada "guerra às drogas"13, ela se declara favorável à legalização da maconha como uma reparação histórica com a população negra. Mulher preta, lésbica e "cria” do Complexo do Alemão (RJ), "graduada em rualogia" como ela declara, Lótus também é rapper, produtora cultural e organizadora de um slam no Rio, batalha realizada mensalmente de forma itinerante em cada Comunidade do Conjunto de Favelas do Alemão.

Tulipa é heterossexual, negra, compositora, rapper, mora no bairro Parolin (periferia de Curitiba). Lírio é hétero, negra, moradora da Vila Torres (periferia de Curitiba). Além das proximidades já demonstradas entre as poetas Tulipa e Lótus, são as únicas que não se posicionaram politicamente nem como direita, nem como esquerda. "Pessoas negras ocupam apenas 6,3\% dos cargos de gerência e 4,7\% de cargos executivos em empresas brasileiras. Quando há inclusão de gênero, ela é de mulheres brancas, e não de negras." (ONU, 2019)². "O feminicídio está crescendo entre as mulheres negras e indígenas, embora esteja diminuindo entre as mulheres brancas, segundo a pesquisadora Jackeline Ap. Romio" (CÂMARA DOS DEPUTADOS, 2018). As opressões raciais e de gênero também aparecem em outras poesias:

\footnotetext{
'Ama de leite é coisa ultrapassada'

Então me diz playboy, qual é a cor da tua empregada? [...]

Burgueses bateram panela porque não tinham o que fazer,

E na quebrada que tem panela, mas não tem o que comer? (Melina Serra, 2018).

Até quando vai continuar?

O negro só serve pro pesado

E a negra pra faxina e para cozinhar (Nick Rodrigues, 2019).
}

\footnotetext{
${ }^{13}$ Termo utilizado pelas instituições repressivas do Estado e pelas mídias que se refere ao encarceramento e assassinatos de pessoas suspeitas de relação com o tráfico de drogas, e que, no entanto, reflete a seletividade penal e o racismo institucional no Brasil, pois a maioria das pessoas presas ou assassinadas são negras e pobres, enquanto os traficantes ricos e brancos ficam, no geral, impunes.

${ }_{14}$ Pesquisa realizada pelo Instituto Ethos, mas publicada na página da Organização das Nações Unidas. Disponível em: https://nacoesunidas.org/evento-discute-desigualdades-de-genero-e-raca-nomercado-de-trabalho-brasileiro/. Último acesso em 27 de nov. de 2019.
} 
Sobre lugares dos quais as slammers se sentem mais a vontade para se apresentarem, apareceram alguns relatos sobre não gostarem de lugares de classe média alta no caso de mulheres pobres; lugares com prevalência de homens; conservadores, e por fim, algumas mulheres negras disseram sentirem-se constrangidas em lugares frequentados por maioria branca. Quatro das poetas relataram já terem sentido desconforto ao falar de algum assunto nos slams, uma com relação ao aborto, outra com relação a sua travestilidade e as outras duas por questões pessoais. As discussões relativas ao aborto, identidade de gênero e diversidade são ainda hoje temas tabus no Brasil, algo que fica evidente em diversas situações que inclusive perpassam a política, como por exemplo, o Projeto de Lei 10577-2018, que prevê a proibição da chamada "ideologia de gênero"15 nas escolas do país. Outro tema tabu no Brasil é a maternidade solo ${ }^{16}$ que estigmatiza muitas mães divorciadas, viúvas e outras que em geral não recebem apoio dos pais no sustento e cuidado dos filhos; Azaleia é bissexual, branca, mãe solo, moradora do bairro Cabral em Curitiba, compositora, rapper, ativista pela visibilidade e reconhecimento da mulher "na cena do hip hop", em suas poesias ela discute bastante questões referentes à maternidade e aborto, nesse sentido ela aponta que "não existe mãe solteira porque mãe não é estado civil”. Todas as mulheres consideram que os slams possibilitam mais empatia e respeito entre homens e mulheres, e entre mulheres. No entanto, relatam que em alguns casos não se realiza: cinco das mulheres já se sentiram constrangidas, desrespeitadas ou assediadas em Slam's, ou enquanto poetas, conforme a poeta Lírio (2019): "Homens sempre são muito machistas e falam mal do feminismo como se quiséssemos eliminálos da Terra e mesmo se dizendo de esquerda o machismo e a homofobia ainda estão enraizadas na maioria dos homens". "Acho desnecessário falar palavrão ou falar de órgão sexual [...] se a pessoa realmente é poeta e quer seguir em frente com Slam deveria abordar sobre vários assuntos até mesmo sobre felicidade, alegria assuntos que ficam faltando". (Tulipa, 2019). Sobre a perspectiva da slammer Tulipa podemos

\footnotetext{
${ }^{15} \mathrm{O}$ termo foi difundido principalmente no período que antecedeu as eleições presidenciais de 2019, por políticos e apoiadores de extrema direita, buscando proibir discussões relativas à sexualidade, violência de gênero e identidade de gênero, pois segundo eles, se tratam de doutrinações que influenciam as crianças.

${ }^{16}$ Entendemos por maternidade solo mães que criam os filhos sozinhas.
} 
também perceber a permanência de certos tabus relativos a assuntos da sexualidade e dos corpos, principalmente para mulheres cis ou trans.

O movimento, segundo as slammers, é importante também para a ocupação de espaços e a tomada de lugares de fala ${ }^{17}$ condizentes com suas vivências, pois, nove poetas disseram que se sentem incomodadas quando homens falam de assuntos que não são de suas vivências, duas não se incomodam e uma se incomoda dependendo do assunto. Conforme as entrevistadas são essenciais as participações de mulheres nos slam's para se "fazerem ouvidas"18, expressarem suas demandas, vivências, interesses, suas produções artísticas e também para as suas representatividades e empoderamento.

\begin{abstract}
Sinto-me muito incomodada quando homens falam de assuntos que não são das suas vivências, refuto publicamente se possível no momento, se não, reclamo nas redes sociais e em outros eventos que eu seja convidada e o tal homem também. O que me chama a atenção é a fragilidade em que se encontra a masculinidade do homem e o descaso em que eles tratam as pautas feministas, como aborto, desigualdade salarial e principalmente a liberdade sexual e de expressão das mulheres (Rosa, 2019).
\end{abstract}

Uma menina falou sobre isso né, sobre se apropriar dos temas, vivências alheias, me sinto desconfortável nesse sentido assim, de ter uma pessoa, principalmente mulher branca assim, falando umas coisas que não cabem a ela sabe? Daí eu fiquei 'meio assim'. Mas nunca constrangida, ou de falar: nossa que tabu (Amarílis, 2019).

Todas acreditam que o Slam ajuda a dar visibilidade para questões sociais. Sobre isso: "Nele podemos falar a realidade que a mídia não mostra. Ele nos dá a voz, empodera o nosso povo, mostra a verdade nua e crua " (Lírio , 2019). "Tira o peso didático. É outra forma de falar que não trazendo estatística, trazendo como arte as pessoas absorvem" (Amarílis, 2019). Todas concordam que o Slam é um movimento empoderador, "importante surdos e ouvintes" (Orquídea, 2019). Notamos assim que as

\footnotetext{
${ }^{17}$ Optou-se por utilizar a palavra "fala" nos termos definidos no Dicionário, segundo o qual a fala não se restringe à oralidade ou à emissão de palavras sonoras, mas também corresponde a expressão, comunicação e significado. A linguagem em geral, contemplando assim o uso de libras. DICIONÁRIO ONLINE. Disponível em: <https://www.dicio.com.br/fala/>. Acesso dia 24 de jun. de 2019.

${ }^{18}$ Optou-se pela utilização do termo entre aspas no sentido de que há mulheres não ouvintes e da preocupação de até que ponto certos termos excluem diversas mulheres com vivências diferentes.
} 
poetas acreditam que os slam's são também ferramentas de transformação social, disputando narrativas.

Poesia marginal é verdade e resistência. O mundo precisa nos ouvir. A transformação da sociedade virá pela cultura de periferia e pela educação que ela está criando nos moldes das quebradas. Vivência empírica e intelectual está se criando dentro da cultura periférica e o slam com a poesia marginal vem para concretizar esse projeto (Rosa, 2019).

O relato acima nos remete a discussão feita por Fleury acerca do reconhecimento de culturas, demonstrando que mulheres, negros, LGBTI's, pobres e outras populações estão inventando, reinventando e ressignificando suas próprias culturas, assim como estão legitimando mesmo que não sejam em vias institucionais, essas práticas culturais.

Relativo ao que as slammers pensam de slam's específicos para mulheres, as entrevistadas consideram importante, pois, trata-se de um espaço de fala feito por e para mulheres, que é empoderador e possibilita "dominar"19 espaços que no geral são dominados por homens. Jasmin é heterossexual, parda, escritora, mestre de cerimônia, blogueira, moradora do bairro Uberaba (periferia de Curitiba) e uma das organizadoras do Slam das Gurias, que segundo ela é um espaço de acolhimento para as slammers.

\section{Conclusão}

O Movimento Slam expõe múltiplas narrativas que ressignificam os estigmas direcionados às culturas ditas populares e periféricas. Conforme todas as entrevistadas responderam, as mulheres possuem pautas diferentes entre si, como é o caso por exemplo, da poeta Azaleia, que aborda em suas poesias e letras musicais o fato de ser mãe solo, da poeta Orquídea , que reivindica a visibilidade da comunidade surda a partir de sua experiência como mulher surda e negra, de Margarida que relata suas experiências de ser uma mulher negra e travesti na sociedade brasileira e nas batalhas de poesia. São mulheres que estão se colocando a partir de lugares e experiências

\footnotetext{
19 Termo utilizado pela slammer Luiza Louge.
} 
próprias, unindo as dimensões intelectuais envolvidas na produção de poesias com as dimensões empíricas da vida de cada uma, elas estão falando de si mesmas, umas para as outras e delas "para o mundo", enfraquecendo as bases machistas, sexistas, misóginas e LGBTI'fóbicas das relações de poder entre gêneros, além de representar parte essencial para a emancipação de outras opressões. As mulheres não são mais apenas as musas que idealizavam, as mulheres são artistas.

Historicamente as mulheres sofreram inúmeras opressões e violências do patriarcado, mas isso não significou que elas foram passivas nem a esses processos e nem mesmo à idealização masculina acerca do que significava "ser mulher". Muitas mulheres sempre desafiaram a norma, mostrando que ninguém cedeu lugar a elas, e sim que seus espaços foram conquistados a partir das lutas de "mulheres transgressoras" como eram chamadas, e que na verdade eram somente mulheres em busca de equidade. O Movimento Feminista por muito tempo marginalizou as injustiças vividas por mulheres que escapassem dos padrões eurocêntricos e heteronormativos, privilegiando apenas as desigualdades entre os gêneros e não outras opressões cometidas entre as próprias mulheres, como as opressões vividas pelas mulheres negras, principalmente em um país como o Brasil, que passou por um longo de período de escravização. A luta das mulheres e a persistência em ocupar espaços têm dado visibilidade cada vez maior às múltiplas vivências e demandas femininas, não no sentido essencializador do "ser mulher", mas enquanto uma série de subjetividades e particularidades de cada uma: gordas, magras, altas, fortes, ouvintes, surdas, brancas, indígenas, negras, jovens, idosas, deficientes, lésbicas, bissexuais, travestis, transexuais, pobres, ricas, artistas, cientistas, bailarinas, donas de casa, mães, são literalmente “mulheres”, plurais e entre aspas, construindo e interpretando suas próprias opressões e agindo no mundo. "Mulher escreva; Você não é só poesia, você é poeta." (Marihu, 2019). 


\section{Referências}

ADELMAN, Mirian. Modernismo e pós-modernidade em vozes feminina. In: CODATO, A. (org). Para viver no Século XXI. Curitiba: SESC Paraná, 2007. Cap. 1. p. 23-46.

BEAUVOUIR, Simone. O segundo sexo. Vol 1. Rio de Janeiro: Nova Fronteira, 2016.

BRITTO, Clovis C. Mulheres e Memória Poética: opressão à flor da letra. Cad. Pagu, no 35 , Campinas, 2010.

CÂMARA DOS DEPUTADOS. Feminicídio cresce entre mulheres negras e indígenas e diminui entre brancas, aponta pesquisadora. Pasta de Direitos Humanos. 2018. Disponível em: <https://www2.camara.leg.br/camaranoticias/noticias/DIREITOSHUMANOS/565155-FEMINICIDIO-CRESCE-ENTRE-MULHERES-NEGRAS-E-

INDIGENAS-E-DIMINUI-ENTRE-BRANCAS,-APONTA-PESQUISADORA.html>.

Acesso em 21 de jun. de 2019.

CARNEIRO, Sueli. Mulheres em Movimento. Estudos Avançados vol. 17, no 49, São Paulo, 2003.

COLLINS, Patricia H. O que é um nome? Mulherismo, Feminismo Negro e, além disso. Cad. Pagu. n. 51. 2017.

DAVIS, Angela. Mulher, Raça e Classe. Trad. Gueto. 2013.

DICIONÁRIO ONLINE, consultado em 24 de jun. de 2019. Disponível em: $<$ https://www.dicio.com.br/fala/>.

FIGUEIREDO, E. Desfazendo o gênero: a teoria queer de Judith Butler. Ver. Criação e Crítica. no 20. 2018.

FLEURY, Laurent. Sociologia da cultura e das práticas culturais. São Paulo: Editora SENAC, 2009.

FREITAG, Raquel M. K.; SEVERO, Cristine G. Severo. Mulheres, Linguagem e Poder. $1^{\circ}$ ed. São Paulo. 2015.

GOFFMAN, Erving. Estigma: Notas sobre a Manipulação da Identidade Deteriorada. Rio de Janeiro: Zahar Editores, 1980.

HIRAMI, Anni C. H. B. Meu Corpo, Minhas Regras: travestis e transexuais em Curitiba. Tese de Conclusão de Curso de Ciências Sociais. Setor de Ciências Humanas. Universidade Federal do Paraná. Curitiba 2015. 
LHULLIER, Louise. A.; CASTRO, Daphne. À flor da pele: posições femininas de dizer o amor. Rev. Subj. 2015, vol.15, n.2, pp. 191-200. ISSN 2359-0769.

ORGANIZAÇÃO DAS NAÇÕES UNIDAS. Evento discute desigualdades de gênero e raça no mercado de trabalho brasileiro. o7 de jun. de 2019. Disponível em: $<$ https://nacoesunidas.org/evento-discute-desigualdades-de-genero-e-raca-nomercado-de-trabalho-brasileiro/>. Acesso em 21 de jun. de 2019.

PARKER, R.; AGGLETON, P. Estigma, Discriminação e Aids. Coleção ABIA, Cidadania e Direitos, n. 1. Rio de Janeiro, ABIA, 2001; v. 57, n. 1, p. 13-24, 2003. Disponível http://www.abiaids.org.br/_img/media/colecao\%2ocidadania\%2odireito.pdf. Acesso em 27 de nov. de 2019.

ROUDINESCO, Eurídice. A Família em Desordem. Ed. o1. Rio de Janeiro. Editora Zahar. 2002.

SOUZA, Natália. S.; PEREIRA, V. C. A escrita da mulher/a escrita feminina na poesia de Maria Teresa Horta. Rev. Estud. Fem., vol.26, no.2, Florianópolis, 2018.

TEIXEIRA, Luiz B. Tese de Doutorado: Da Lama ao Caos: A urbanização de Curitiba vista do Bolsão Audi-União. Universidade Federal do Paraná. Curitiba, 2019. Acessada diretamente com o autor.

THOMAZ, D. O Globo. Época. Reduzida por homicídios, a expectativa de vida de um transexual no Brasil é de apenas 35 anos. 30 de jan. de 2018. Disponível em: $<$ https://epoca.globo.com/brasil/noticia/2018/o1/reduzida-por-homicidios-expectativade-vida-de-um-transexual-no-brasil-e-de-apenas-35-anos.html>. Acesso em 21 de jun. de 2019 .

WOOLF, Virginia. Um teto todo seu. São Paulo: Tordesilhas, 2014. 